\title{
Analysis of runoff variation according to subbasin division
}

\author{
M. Yu, C. Choi, J. Ji \& J. Yi \\ Department of Civil and Transportation Engineering, \\ Ajou University, South Korea
}

\begin{abstract}
Unlike in the past, recently in Korea, heavy rainfall has often been observed out of the rainy season. In terms of patterns, rainfall becomes more focused spatially, and rainfall events occur frequently that exceed the recorded amount of past rainfall by frequency. Consequently, flood disasters happen more often, leading to great economic losses. In this research, flood runoff variation is analyzed according to subbasin divisions. The HEC-HMS model is used to simulate a rainfall-runoff process. The inverse distance weighted (IDW) method is used to distribute the observed rainfall to an entire basin, and the modified Clark (ModClark) method is used to simulate runoff using spatially distributed rainfall and geographic data. Furthermore, the runoff variation pattern is reviewed and compared with the observed data according to the number of subbasin divisions. The results show that the peak runoff increases and the peak time decreases as the number of subbasins increases. However, neither the peak runoff nor the peak time shows these patterns if the number of subbasin divisions exceed nine. Keywords: HEC-HMS, ModClark, subbasin division, IDW.
\end{abstract}

\section{Introduction}

Unlike in the past, in Korea, heavy rainfall has often recently been observed out of the rainy season. In terms of patterns, rainfall has become more focused in spatially, and rainfall events occur frequently that exceed the recorded amount of past rainfall by frequency. All of these tendencies are growing stronger by time. For example, on September 21, 2010, more than $100 \mathrm{~mm}$ an hour of rainfall in the central region of Korea; this caused severe damage, interrupting subway operation and flooding houses. In Seoul, the amount of rainfall was recorded as 
$259.2 \mathrm{~mm}$ in a day, the highest record for late September since official weather observation began in 1908. In the southwestern part of Seoul and Incheon, rainfall at a rate of more than $100 \mathrm{~mm}$ an hour; the amount of rainfall was $287.5 \mathrm{~mm}$ in Hwagok-dong, Gangseo-gu, and $86.5 \mathrm{~mm}$ in Banghak-dong, Dobong-gu, both located in Seoul, showing a significant regional difference. This illustrates that rainfall has become more concentrated in both time and space. As this trend develops, rainfall more often exceeds the recorded amount by frequency, which is calculated from the past observation data. Given this context, it is important to enhance the accuracy of the rainfall-runoff model by reflecting changing flood patterns.

The currently used discharge analysis model by unit hydrograph uses the average rainfall in the basin area as input. This model has the limitation that rainfall data are derived from observation points in particular places. Accordingly, point-based rainfall data are converted to area-based rainfall data to calculate the flooding amount. However, there is a growing need to develop a model that can estimate the spatial distribution of rainfall using point-based rainfall data, especially in places with complex topographies like Korea.

In this study, the inverse distance weighted (IDW) method is applied to utilize rainfall observation data for a broader region, and the modified Clark model [1] is used to simulate rainfall based on spatially distributed rainfall and topography data. In addition, a discharge simulation was conducted according to subbasin division, without modifying the discharge parameter calculated from actual observation data, in order to examine the changing pattern of rainfall discharge according to the number of subbasin divisions. The simulation result is reviewed, analyzed, and compared with the observation data to suggest an optimal method of dividing subbasins.

\section{Basic theories}

\subsection{The modified clark (ModClark) model}

The ModClark model adopts the basic principle of the Clark rainfall-runoff model, but adds a simulation function to calculate the discharge volume throughout the basin by adding up the discharge amount of each grid at the basin outlet using the spatially distributed rainfall data and topography data. Fig. 1 illustrates the concepts of the ModClark model [2]. To apply this model, information on the surface area of each cell and the distance between each cell and the basin outlet is needed. Concentration time to basin outlet varies by cell, and is proportionate to the distance. Eqn. (1) shows how to estimate the concentration time to reach the basin outlet:

$$
t_{c e l l}=T_{c} \frac{d_{c e l l}}{d_{\max }}
$$

$T_{c}$ indicates the entire concentration time to reach the basin, $d_{c e l l}$ indicates the concentration time between each cell and the basin outlet, and $d_{\text {max }}$ indicates the distance between the basin outlet and the farthest grid. 


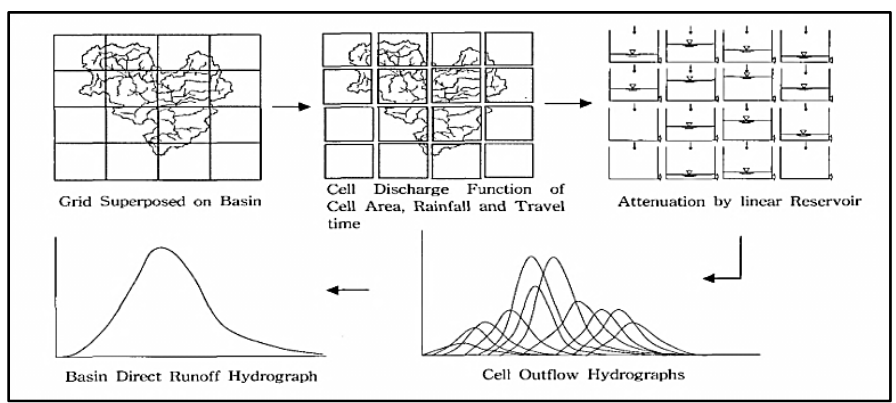

Figure 1: Conceptual diagram of the ModClark model.

Unlike the Clark model, the ModClark model calculates the concentration time for each cell, giving a more accurate estimate of the concentration time from all areas of the basin. It is assumed that the amount of discharge is proportionate to the surface area of the cell. Delayed excess rainfall is tracked by a linear reservoir as follows:

$$
O_{i}=\left[\frac{\Delta t}{K+0.5 \Delta t}\right] I_{a v g}+\left[1-\frac{\Delta t}{K+0.5 \Delta t}\right] O_{i-1}
$$

Here, $O_{i}$ indicates direct runoff at time $i, K$ is a reservoir constant, and $I_{\text {avg }}$ indicates the average inflow between time $i-1$ and $i . \Delta t$ indicates the time interval. In this study, ArcGIS and HEC-GeoHMS [3] are used to calculate hydrological and topographical data to apply the ModClark method.

\subsection{Inverse distance weighted (IDW) method}

The IDW method is applied to estimate the spatial rainfall data from point-based observation data. The basic assumption is that two spatially approximate points have similar rainfall data, but the similarity lessens as the distance between the two points grows. Eqn. (3) describes the basic concept of the IDW method:

$$
u(x)=\frac{\sum_{i=0}^{N} \omega_{i}(x) u_{i}}{\sum_{i=0}^{N} \omega_{i}(x)}
$$

Here, $u(x)$ indicates value to be estimated at point $x, N$ is the number of observation points, $\omega_{i}(x)$ is the weighted value to be applied to observation point $x_{i}$, and $u_{i}$ represents the observation data at point $x_{i} . \omega_{i}(x)$ decreases as the distance becomes greater, as shown in eqn. (4):

$$
\omega_{i}(x)=\frac{1}{d\left(x, x_{i}\right)^{p}}
$$

where $d\left(x, x_{i}\right)$ indicates the distance between observation point $x_{i}$ and estimate point $x$. Here, $p$ is the power parameter, that is, the extent of changes in weighted value according to distance; it is also a main parameter of the IDW method. 


\section{Rainfall-runoff model in test basin}

\subsection{Test basin}

The basin of the Pyeongchang River, the primary branch of the Han River, was selected as a test basin. The Han River basin is located in the central part of the peninsula, covering the area between latitude $36^{\circ} 30^{\prime}-38^{\circ} 55^{\prime} \mathrm{N}$ and longitude $126^{\circ} 24^{\prime}-129^{\circ} 02^{\prime} \mathrm{E}$. The basin area is $26,356 \mathrm{~km}^{2}\left(8,455 \mathrm{~km}^{2}\right.$ is in the territory of North Korea); the flow path is $481.7 \mathrm{~km}$ long, $55.8 \mathrm{~km}$ on average; and the basin shape factor is 0.119 . It is the largest river in South Korea, covering approximately $23 \%$ of the country's territory. The Pyeongchang River basin covers $1,773.39 \mathrm{~km}^{2}$. Its average basin slope is $39.91 \%$, the shape factor is 0.58 , and the drainage density is 1.71 . The average altitude is EL. $591.53 \mathrm{~m}$, while the maximum altitude is EL. $1,570 \mathrm{~m}$.

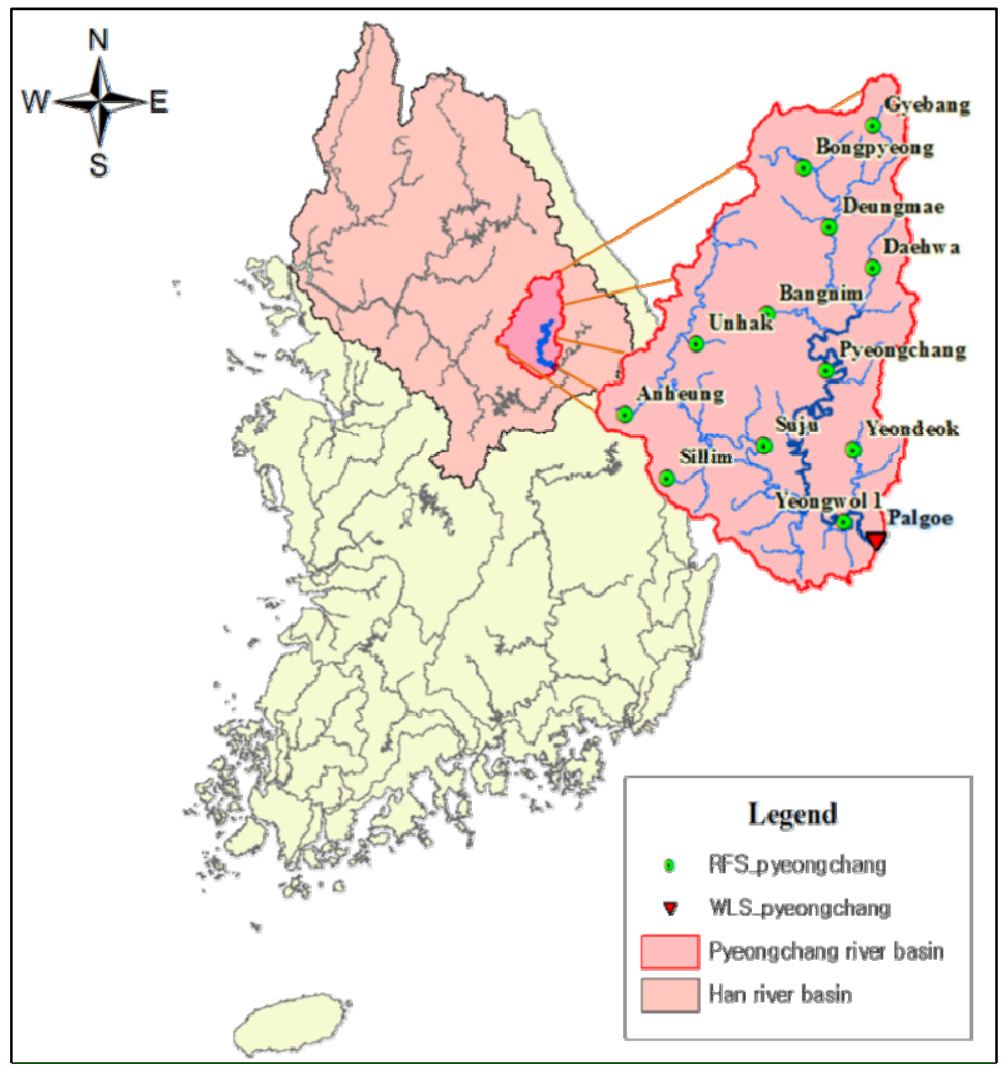

Figure 2: Basin of Pyeongchang river. 


\subsection{Preliminary treatment}

The digital elevation model (DEM) was used to establish the HEC-GeoHMS model, which extracts hydrologic property factors of a basin area based on GIS data. To prevent flow interruption due to lower elevation, repeated calculation was made in the DEM to fill sink areas ("Fill Sinks") until the flow direction could be defined (Fig. 3). Once the flow direction was decided, the number of accumulated flows for each cell could be calculated to map out the pattern of the main river (Fig. 4). Fig. 5 illustrates the formation of the river basin for each factor through river networks built from the accumulated data on flows and flow directions. A detailed soil map and land cover map (Fig. 6 and 7) were used to identify topographical factors and parameters, and the SCS CN coefficient is calculated (Fig. 8).

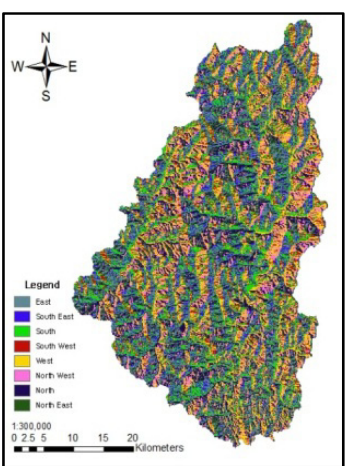

Figure 3: Flow direction.

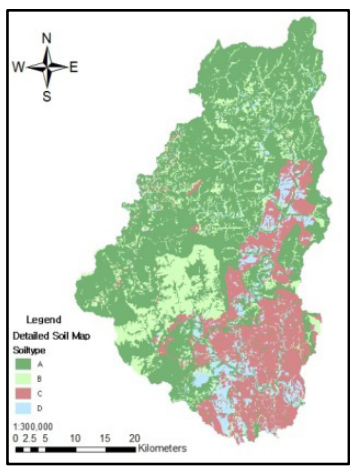

Figure 6:

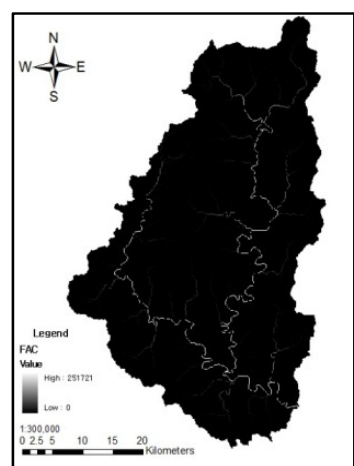

Figure 4: Flow accumulation.

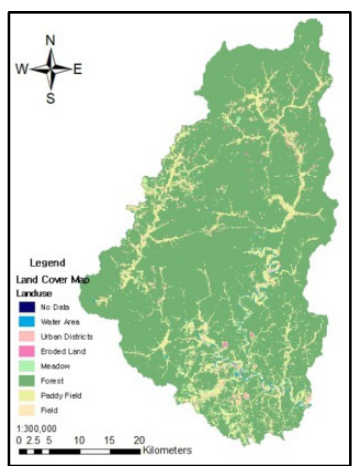

Figure 7: Land cover map.

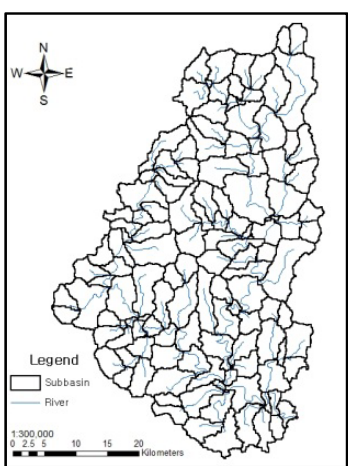

Figure 5: Division of subbasin.

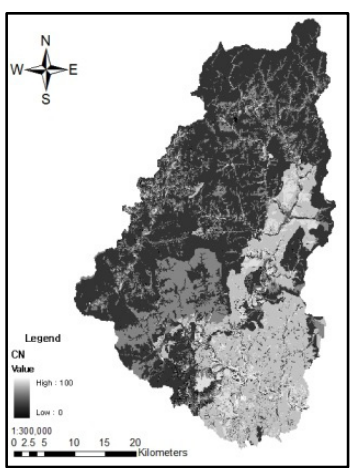

Figure 8: $\quad$ SCS CN. soil map. 


\section{Simulation of rainfall-runoff model by subdivisions}

\subsection{Subbasin division of the test basin}

For simulation, the basin area was divided into nine different numbers of subdivisions: $1,3,5,6,7,9,10,12$ or 15 . The subbasins had an equal surface area, and the watershed was set at the confluence point where the Pyeongchang River and the Jucheon river meet, and the Palgye observation point, that is, an outlet of the test basin. The areas of the subdivisions were divided so that they would be as equal as possible, considering the stream order, basin watershed, and so forth. Table 1 lists the areas of the subbasins, their area ratio, flow path $(L)$, concentration time according to the Clark method $\left(T_{c}\right)$, and storage constant $(K)$.

Table 1: $\quad$ Subbasin data and parameters.

\begin{tabular}{|c|c|c|c|c|c|c|c|c|c|}
\hline $\begin{array}{l}\text { Sub- } \\
\text { basin }\end{array}$ & $\begin{array}{c}\text { Area } \\
\left(\mathrm{km}^{2}\right)\end{array}$ & $\begin{array}{c}\mathrm{L} \\
(\mathrm{km})\end{array}$ & $\begin{array}{c}T_{c} \\
(h r)\end{array}$ & $\begin{array}{c}\mathrm{K} \\
(h r)\end{array}$ & $\begin{array}{l}\text { Sub- } \\
\text { basin }\end{array}$ & $\begin{array}{c}\text { Area } \\
\left(\mathrm{km}^{2}\right)\end{array}$ & $\begin{array}{c}\mathrm{L} \\
(\mathrm{km})\end{array}$ & $\begin{array}{c}T_{c} \\
(h r)\end{array}$ & $\begin{array}{c}\mathrm{K} \\
(h r)\end{array}$ \\
\hline $1-1$ & $1,764.6$ & 134.2 & 17.8 & 30.9 & & & & & \\
\hline $3-1$ & 463.4 & 63.2 & 8.4 & 11.8 & $3-3$ & 605.5 & 76.5 & 10.1 & 16.3 \\
\hline $3-2$ & 695.8 & 71.0 & 9.4 & 11.3 & & & & & \\
\hline $5-1$ & 273.7 & 25.3 & 3.3 & 2.7 & $5-4$ & 295.4 & 33.8 & 4.5 & 4.0 \\
\hline $5-2$ & 352.8 & 55.9 & 7.4 & 10.7 & $5-5$ & 310.1 & 26.6 & 5.7 & 6.0 \\
\hline $5-3$ & 532.7 & 53.0 & 7.0 & 7.0 & & & & & \\
\hline $6-1$ & 273.7 & 25.3 & 3.3 & 2.7 & $6-4$ & 315.7 & 29.9 & 4.0 & 3.3 \\
\hline $6-2$ & 236.9 & 49.1 & 6.5 & 11.2 & $6-5$ & 295.4 & 33.8 & 4.5 & 4.0 \\
\hline $6-3$ & 333.0 & 30.0 & 4.0 & 3.2 & $6-6$ & 310.1 & 42.8 & 5.7 & 6.0 \\
\hline $7-1$ & 176.5 & 22.0 & 2.9 & 2.4 & $7-5$ & 315.7 & 29.9 & 4.0 & 3.3 \\
\hline $7-2$ & 239.6 & 24.3 & 3.2 & 2.6 & $7-6$ & 312.7 & 28.8 & 3.8 & 3.1 \\
\hline $7-3$ & 300.7 & 40.5 & 5.4 & 5.4 & $7-7$ & 202.5 & 26.6 & 3.5 & 3.0 \\
\hline $7-4$ & 217.0 & 23.1 & 3.1 & 2.5 & & & & & \\
\hline $9-1$ & 176.4 & 22.0 & 2.9 & 2.4 & $9-6$ & 265.4 & 27.0 & 3.6 & 2.9 \\
\hline $9-2$ & 218.9 & 24.3 & 3.2 & 2.6 & $9-7$ & 205.1 & 12.7 & 1.7 & 1.2 \\
\hline $9-3$ & 158.4 & 34.1 & 4.5 & 5.5 & $9-8$ & 186.5 & 24.6 & 3.3 & 2.8 \\
\hline $9-4$ & 208.0 & 23.6 & 3.1 & 2.5 & $9-9$ & 123.5 & 18.1 & 2.4 & 2.0 \\
\hline $9-5$ & 222.4 & 20.3 & 2.7 & 2.1 & & & & & \\
\hline $10-1$ & 154.1 & 12.0 & 1.6 & 1.2 & $10-6$ & 265.4 & 27.0 & 3.6 & 2.9 \\
\hline $10-2$ & 119.6 & 13.3 & 1.8 & 1.3 & $10-7$ & 146.3 & 24.4 & 3.2 & 2.9 \\
\hline $10-3$ & 189.8 & 38.0 & 5.0 & 6.3 & $10-8$ & 149.1 & 9.3 & 1.2 & 0.9 \\
\hline $10-4$ & 209.1 & 24.9 & 3.3 & 2.7 & $10-9$ & 163.3 & 19.5 & 2.6 & 2.1 \\
\hline $10-5$ & 221.2 & 19.0 & 2.5 & 1.9 & $10-10$ & 146.8 & 23.3 & 3.1 & 2.7 \\
\hline $12-1$ & 154.1 & 12.0 & 1.6 & 1.2 & $12-7$ & 118.2 & 9.2 & 1.2 & 0.9 \\
\hline $12-2$ & 119.6 & 13.3 & 1.8 & 1.3 & $12-8$ & 147.2 & 9.6 & 1.3 & 0.9 \\
\hline $12-3$ & 95.3 & 25.2 & 3.3 & 3.8 & $12-9$ & 146.3 & 24.4 & 3.2 & 2.9 \\
\hline $12-4$ & 116.2 & 18.8 & 2.5 & 2.1 & $12-10$ & 176.2 & 18.8 & 2.5 & 1.9 \\
\hline $12-5$ & 187.4 & 18.9 & 2.5 & 1.9 & $12-11$ & 159.4 & 15.2 & 2.0 & 1.5 \\
\hline
\end{tabular}


Table 1: $\quad$ Continued.

\begin{tabular}{|c|c|c|c|c|c|c|c|c|c|}
\hline $12-6$ & 221.2 & 19.0 & 2.5 & 1.9 & $12-12$ & 123.5 & 18.1 & 2.4 & 2.0 \\
\hline $15-1$ & 154.1 & 12.0 & 1.6 & 1.2 & $15-9$ & 118.2 & 27.0 & 3.6 & 3.9 \\
\hline $15-2$ & 119.6 & 13.3 & 1.8 & 1.3 & $15-10$ & 147.2 & 23.7 & 3.1 & 2.8 \\
\hline $15-3$ & 76.4 & 15.4 & 2.0 & 1.7 & $15-11$ & 90.3 & 21.1 & 2.8 & 2.7 \\
\hline $15-4$ & 69.7 & 22.5 & 3.0 & 3.6 & $15-12$ & 139.1 & 8.6 & 1.1 & 0.8 \\
\hline $15-5$ & 104.5 & 17.9 & 2.4 & 2.0 & $15-13$ & 163.9 & 17.0 & 2.2 & 1.7 \\
\hline $15-6$ & 132.6 & 7.0 & 0.9 & 0.6 & $15-14$ & 102.0 & 15.2 & 2.0 & 1.6 \\
\hline $15-7$ & 102.2 & 15.9 & 2.1 & 1.7 & $15-15$ & 110.2 & 14.8 & 2.0 & 1.5 \\
\hline $15-8$ & 134.7 & 19.0 & 2.5 & 2.0 & & & & & \\
\hline
\end{tabular}

\subsection{Spatial distribution of rainfall based on the IDW method}

To estimate the spatial distribution of rainfall based on data from 12 observation points, IDW was used; this is the most commonly used spatial interpolation method for estimating spatial information based on point observation data. As eqn. (4) shows, the inverse distance squared weighting (IDSW) method was used; this sets the main power parameter at 2 [4].

In HEC-HMS, grid data can only be entered in data storage system (DSS) format [5]. For this study, the hourly rainfall data (in 10min intervals) from the 12 observation points was spatially interpolated and printed out in ASCII file format. It was then converted to a DSS file for data entry. The rainfall data shown on the TM projection of ArcMap can be printed out to illustrate the spatial distribution of rainfall over the entire basin area using each observation point (Fig. 9). The data converted to DSS grid file can be shown in the viewer DSSVue (Fig. 10).

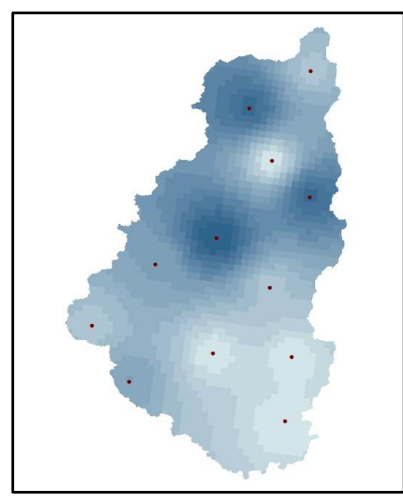

Figure 9: Spatial distribution of rainfall in the $\mathrm{TM}$ projection of ArcMap (rainfall data from September 20, 2010).

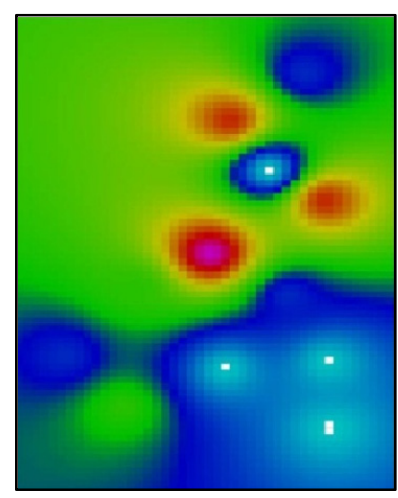

Figure 10: Spatial distribution of rainfall in the DSS grid format (rainfall data from September 20, 2010). 


\subsection{Simulation result of each rainfall event}

Simulation was conducted for different cases of subbasin division for three rainfall events in September 2007, July 2009, and September 2010. The simulation results, including changes in peak flow and peak time by different number of subbasins, were analyzed.

\subsubsection{Case one: rainfall event in september 2007}

Fig. 11 illustrates the simulation result of rainfall discharge in the subbasins for the rainfall event in September 2007. Table 2 and Fig. 12 show the peak flow estimates $\left(Q_{p}\right)$ in each case, their ratio to the observation data, and the time difference between the peak time estimate $\left(T_{p}\right)$ and observed peak time.

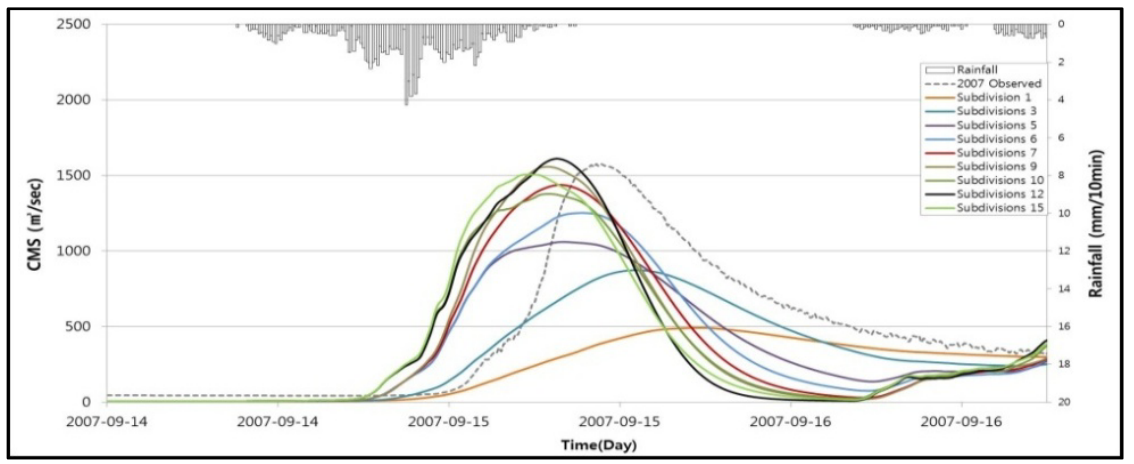

Figure 11: Simulation results by number of subdivisions.

The simulation results show that, in general, the peak flow increases and the peak time is reached earlier as the number of subdivisions increases. The peak flow increased until the number of subdivisions reached nine, and after that, it showed a rather irregular pattern. In terms of peak time, it became earlier until the number of subdivisions was nine-except at five-and reached it earlier except in the case of 12 subdivisions.

Table 2: $\quad$ Changes in peak flow and peak time by number of subdivisions.

\begin{tabular}{|c|c|c|c|c|}
\hline Subdivision & $\mathrm{Q}_{\mathrm{p}}\left(\mathrm{m}^{3} / \mathrm{s}\right)$ & Ratio (\%) & $\mathrm{T}_{\mathbf{p}}(\mathrm{Time})$ & $\begin{array}{c}\text { Time Difference } \\
(\mathrm{hr})\end{array}$ \\
\hline \hline Observed & $1,575.49$ & - & $9 / 1515: 20$ & - \\
\hline Single Basin & 492.92 & $31.3 \%$ & $9 / 1522: 40$ & $07: 20$ \\
\hline Subdivisions 3 & 873.34 & $55.4 \%$ & $9 / 1518: 10$ & $02: 50$ \\
\hline Subdivisions 5 & $1,060.50$ & $67.3 \%$ & $9 / 1513: 00$ & $-02: 20$ \\
\hline Subdivisions 6 & $1,252.10$ & $79.5 \%$ & $9 / 1514: 20$ & $-01: 00$ \\
\hline Subdivisions 7 & $1,438.20$ & $91.3 \%$ & $9 / 1512: 50$ & $-02: 30$ \\
\hline Subdivisions 9 & $1,558.40$ & $98.9 \%$ & $9 / 1512: 00$ & $-03: 20$ \\
\hline Subdivisions 10 & $1,378.40$ & $87.5 \%$ & $9 / 1512: 00$ & $-03: 20$ \\
\hline Subdivisions 12 & $1,611.60$ & $102.3 \%$ & $9 / 1512: 30$ & $-02: 50$ \\
\hline Subdivisions 15 & $1,506.70$ & $95.6 \%$ & $9 / 1510: 40$ & $-04: 40$ \\
\hline
\end{tabular}




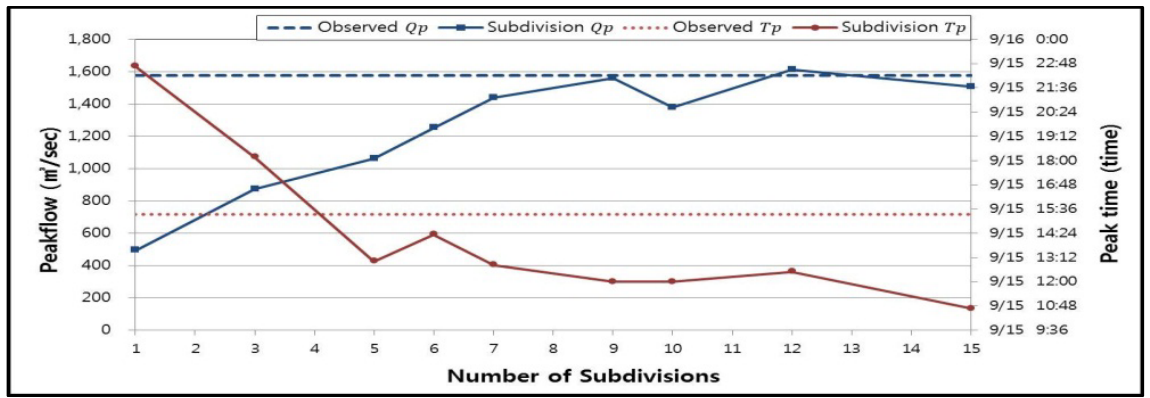

Figure 12: $\quad$ Peak flow and peak time by number of subdivisions.

Compared to the observed outflow hydrograph, the peak flow was closest to the observation data $\left(1,575.5 \mathrm{~m}^{3} / \mathrm{s}\right)$ in the case of nine subdivisions $\left(1,558.4 \mathrm{~m}^{3} /\right.$ $\mathrm{s})$; as for the peak time, it was most approximate to the observation data $(15: 20)$ in the case of six subdivisions (14:20).

Table 3: $\quad$ Changes in peak flow and peak time by number of subdivisions.

\begin{tabular}{|c|c|c|c|c|}
\hline Subdivision & $\mathrm{Q}_{\mathrm{p}}\left(\mathrm{m}^{3} / \mathrm{s}\right)$ & Ratio (\%) & $\mathrm{T}_{\mathrm{p}}(\mathrm{Time})$ & $\begin{array}{c}\text { Time Difference } \\
(\mathrm{hr})\end{array}$ \\
\hline \hline Observed & $1,770.31$ & - & $7 / 1002: 30$ & - \\
\hline Single Basin & 502.60 & $28.4 \%$ & $7 / 1009: 40$ & $07: 10$ \\
\hline Subdivisions 3 & 904.44 & $51.1 \%$ & $7 / 1006: 20$ & $03: 50$ \\
\hline Subdivisions 5 & $1,018.80$ & $57.5 \%$ & $7 / 1004: 30$ & $02: 00$ \\
\hline Subdivisions 6 & $1,392.90$ & $78.7 \%$ & $7 / 1003: 30$ & $01: 00$ \\
\hline Subdivisions 7 & $1,418.70$ & $80.1 \%$ & $7 / 1002: 30$ & $00: 00$ \\
\hline Subdivisions 9 & $1,479.60$ & $83.6 \%$ & $7 / 1001: 40$ & $-00: 50$ \\
\hline Subdivisions 10 & $1,405.60$ & $79.4 \%$ & $7 / 1001: 50$ & $-00: 40$ \\
\hline Subdivisions 12 & $1,891.70$ & $106.9 \%$ & $7 / 1001: 40$ & $-00: 50$ \\
\hline Subdivisions 15 & $1,484.90$ & $83.9 \%$ & $7 / 1000: 30$ & $-02: 00$ \\
\hline
\end{tabular}

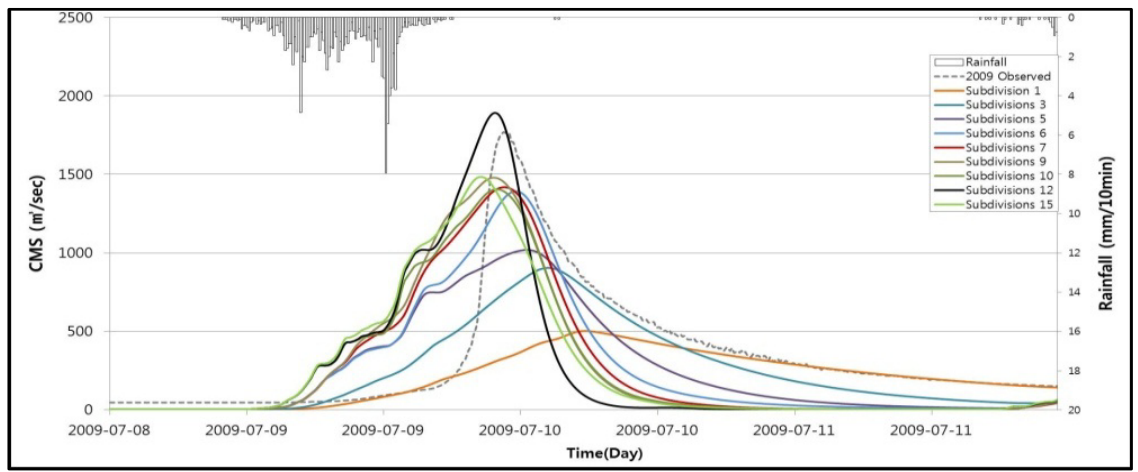

Figure 13: Simulation results by number of subdivisions. 


\subsubsection{Case two: rainfall event in July 2009}

The peak flow increased until the number of subdivisions reached 9 , and showed similar volume at numbers of subdivisions between 6 and 15, except at 12 . The peak time was reached earlier until the number of subdivisions reached 9 , stayed stable until the number was 12 , and then became earlier again.

Compared to the observed outflow hydrograph, the peak flow was closest to the observation data $\left(1,770.31 \mathrm{~m}^{3} / \mathrm{s}\right)$ in the case of 12 subdivisions $\left(1,891.70 \mathrm{~m}^{3} / \mathrm{s}\right)$; the peak time with 7 subdivisions $(2: 30)$ coincided with the observation data (02:30).

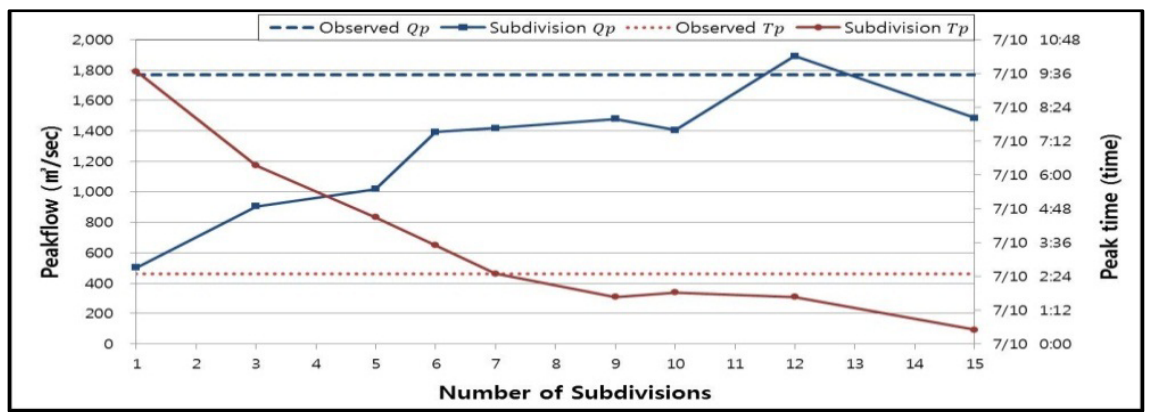

Figure 14: Peak flow and peak time by number of subdivisions.

\subsubsection{Case three: rainfall event in September 2010}

The peak flow increased until the number of subdivisions reached nine, declined, and then reversed again. Regarding peak time, it was reached earlier until the number of subdivision reached 9 , stayed stable until the number reached 10 , and then became earlier after the number of subdivisions reached 12 .

Compared with the observed outflow hydrograph, the peak flow was closest to the observation data $\left(3,513.7 \mathrm{~m}^{3} / \mathrm{s}\right)$ in the case of 15 subdivisions $\left(3,536.9 \mathrm{~m}^{3} /\right.$ $\mathrm{s})$, and the peak time in the case of 6 subdivisions $(03: 20)$ matched the observation data $(03: 20)$.

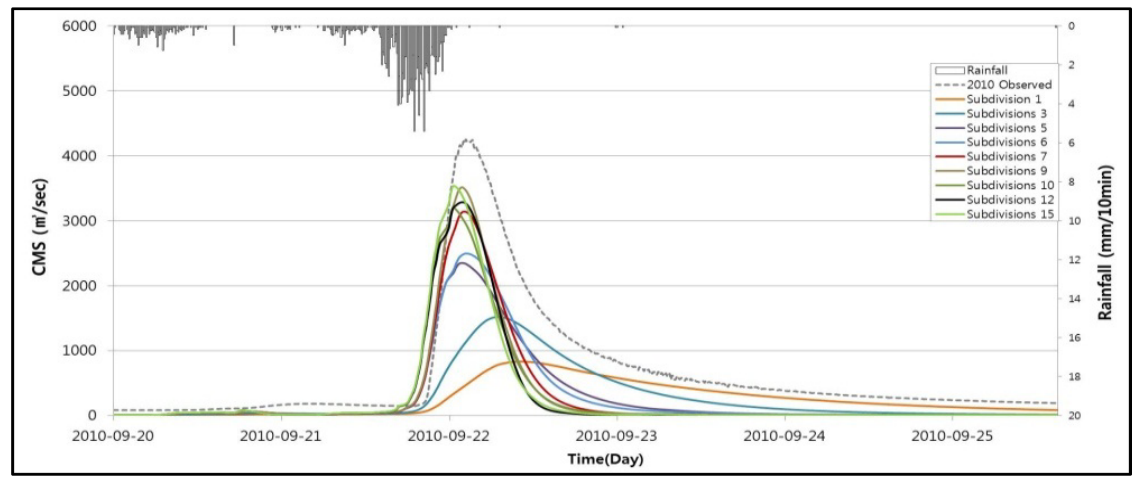

Figure 15: Simulation results by number of subdivisions. 
Table 4: $\quad$ Changes in peak flow and peak time by number of subdivisions.

\begin{tabular}{|c|c|c|c|c|}
\hline Subdivision & $\mathrm{Q}_{\mathrm{p}}\left(\mathrm{m}^{3} / \mathrm{s}\right)$ & Ratio (\%) & $\mathrm{T}_{\mathrm{p}}($ Time) & $\begin{array}{c}\text { Time Difference } \\
(\mathrm{hr})\end{array}$ \\
\hline \hline Observed & $4,249.96$ & - & $9 / 2203: 20$ & - \\
\hline Single Basin & 831.01 & $19.6 \%$ & $9 / 2211: 10$ & $07: 50$ \\
\hline Subdivisions 3 & $1,518.10$ & $35.7 \%$ & $9 / 2208: 00$ & $04: 40$ \\
\hline Subdivisions 5 & $2,348.80$ & $55.3 \%$ & $9 / 2202: 50$ & $-00: 30$ \\
\hline Subdivisions 6 & $2,493.80$ & $58.7 \%$ & $9 / 2203: 20$ & $00: 00$ \\
\hline Subdivisions 7 & $3,139.90$ & $73.9 \%$ & $9 / 2203: 10$ & $-00: 10$ \\
\hline Subdivisions 9 & $3,513.70$ & $82.7 \%$ & $9 / 2202: 50$ & $-00: 30$ \\
\hline Subdivisions 10 & $3,198.70$ & $75.3 \%$ & $9 / 2201: 30$ & $-01: 50$ \\
\hline Subdivisions 12 & $3,284.20$ & $77.3 \%$ & $9 / 2202: 50$ & $-00: 30$ \\
\hline Subdivisions 15 & $3,536.90$ & $83.2 \%$ & $9 / 2201: 40$ & $-01: 40$ \\
\hline
\end{tabular}

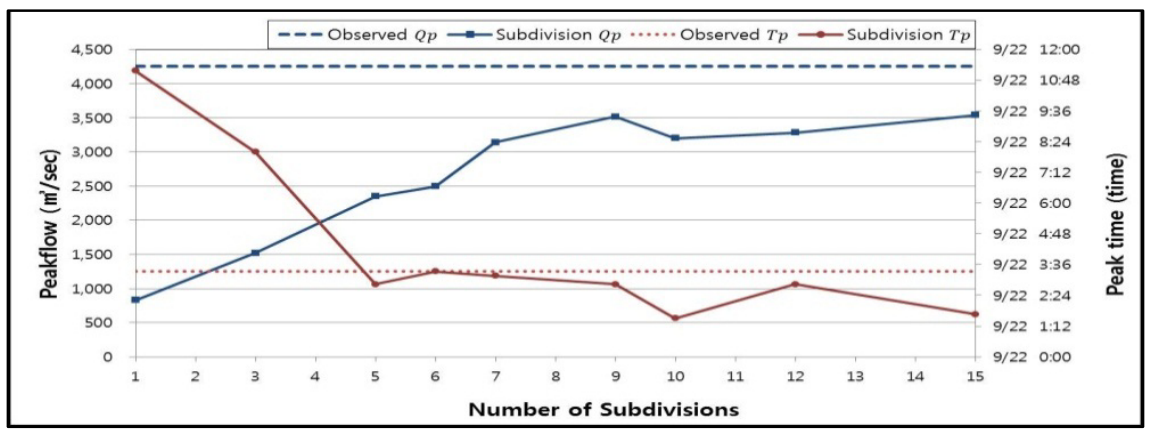

Figure 16: Peak flow and peak time by number of subdivisions.

\section{Conclusion}

The objectives of this study were to apply the rainfall-runoff model to examine and analyze rainfall discharge patterns according to number of subdivisions in a basin area, and to suggest an optimal way of dividing subdivisions through comparison with the observation data. Accordingly, a simulation was conducted in the Pyeongchang River basin area.

The ModClark model was applied, and rainfall data were processed through the IDW method, estimating the spatial data based on point observation data. The hydrological and topographical factors were identified through GIS. The basin was divided into equal areas of $3,5,6,7,9,10,12$ and 15 subdivisions, representing nine cases in total. For each case, rainfall-runoff simulation was conducted for three rainfall events in September 2007, July 2009, and September 2010. To examine the influence of subdivision on peak flow and peak time, the optimization trial of HEC-HMS was not applied.

The simulation results indicated that the peak flows tended to increase and the peak time shifted earlier as the number of subdivisions increased; this tendency weakened after the number of subdivisions reached a certain point. In three 
rainfall events, comparison between the estimated and the observation data suggested that nine subdivisions (equal area ratio $11.1 \%$ ) would be an optimal number of subdivisions to estimate peak flow, and six (equal area ratio 16.7\%) and seven (equal area ratio 14.3\%) subdivisions would be optimal numbers of subdivisions to estimate peak time.

The simulation was limited to the Pyengchang River basin area, and for a broader application of the findings, it will be necessary to conduct additional research and analysis in various settings, including mountainous and flatland basin areas.

\section{Acknowledgements}

This study was financially supported by the Construction Technology Innovation Program (08-Tech-Inovation-F01) through the Research Center of Flood Defence Technology for Next Generation in Korea Institute of Construction \& Transportation Technology Evaluation and Planning (KICTEP) of Ministry of Land, Transport and Maritime Affairs (MLTM).

\section{References}

[1] Kull, D. W., and Feldman, A. D., Evolution of Clark's Unit Graph Method to Spatially Distributed Runoff. Journal of Hydrologic Engineers. ASCE, Vol. 3, No.1, pp. 9-19, 1998.

[2] Ahn, S. J., and Yoon, S. H., Runoff Analysis using ModClark Model. Journal of Korea Water Resources Association. Vol.38, No.3, pp. 245-257, 2005.

[3] Hydrologic Engineering Center. HEC-GeoHMS: Geospatial Hydrologic Modeling Extension, User's Manual. U.S. Army Corps of Engineers, Davis, CA, 2010.

[4] Donald Shepard, A two-dimensional interpolation function for irregularlyspaced data, Proceedings of the 1968 ACM National Conference, pp. 517$524,1968$.

[5] Hydrologic Engineering Center. HEC-HMS: Hydrologic Modeling System, User's Manual. U.S. Army Corps of Engineers, Davis, CA, 2010. 